\title{
Developing E-Learning Environments for Field Practitioners and Developmental Researchers: A Third Revision of an ISD Model to Meet E-Learning and Distance Learning Innovations
}

\author{
Abdellatif Elsafy Elgazzar1,2 \\ ${ }^{1}$ College of Graduate Studies, Arabian Gulf University, Manama, Kingdom of Bahrain \\ ${ }^{2}$ Women Faculty (Arts, Science, \& Education), Ain Shams University, Cairo, Egypt \\ Email: dr.a latif@hotmail.com, abdellatifeag@agu.edu.bh
}

Received October 2013

\begin{abstract}
The problem of this research was stated as "there is a need to revise Elgazzar (2002) ISD model to meet instructional development and developmental research on eLearning and distance learning innovations". Developmental research method was implemented that included action research and case studies to report revisions of the Elgazzar (2002) ISD model to reach the new revised ISD model. Participants were (8) PhD students used the 2002 model under the author supervision (7 of them completed their theses). An open questions Questionnaire was given to participants to report revisions needed while applying Elgazzar (2002) in their development of eLearning environments on the Learning Management Systems (LMS). The author put the commonly changes and developed a prototype ISD model. The final ISD model was refereed by two Associate Professors specialized in Educational Technology: eLearning and Instructional Design from the Program of Distance Teaching and Training, Arabian Gulf University. The research has resulted in a third revised Elgazzar (2013) ISD model for developing eLearning and distance learning environments. The research includes Figures, References, and recommendations.
\end{abstract}

\section{Keywords}

Instructional Design Models; Instructional Development; Developmental Research Method; Elgazzar (1995) ISD Model; Elgazzar (2002) ISD Model; E-Learning and Distance Learning Environments; Elgazzar (2013) ISD Model; Developing E-Learning Environments

\section{Introduction}

Many developments have taken place in the field of Educational/Instructional Technology (ET/IT) in theory,

How to cite this paper Elgazzar, A.E. (2014) Developing E-Learning Environments for Field Practitioners and Developmental Researchers: A Third Revision of an ISD Model to Meet E-Learning and Distance Learning Innovations. Open Journal of Social Sciences, 2, 29-37. http://dx.doi.org/10.4236/jss.2014.22005 
practice, and research, and many innovations such as eLearning and distance learning have been growing in education and training in schools and higher education. It has become a self contained field of applied science in educational sciences, that has knowledge, theory, design theories, instructional design/development (ISD) models, resources, researchers, research methods, professionals, and scientific bodies; just similar to any scientific field of technological fields. ET/IT is dynamically adaptable to respond to any developments in technology such as information and communication technology (ICT) that take place in the society. Systems approach is the core of technology since it is defined as the systematic applications of organized knowledge to practical purposes in society Galbraith [1]. The author has extended Galbraith's theory of technology to be defined as a dynamic process based on the application of structured applied knowledge, using human and non-human resources, the systems approach, to achieve practical purposes for the society (see Elgazzar [2]). In instructional technology, the systems approach is implemented through the instructional development by applying ISD models. So, ISD models are considered foundations and core of instructional development or instructional design, as they are used interchangeably in this paper. ISD models have got the concern of instructional technology scholars and many ISD models have been developed around us in the field since the 70s of the past century. These ISD models have been surveyed, analyzed, and classified by many scholars since late seventies of the past century Gustafson \& Branch [3]. It isn't the purpose here to review ISD models, but rather defines the function of ISD models in both instructional systems design/development and developmental research methods.

\section{ISD Models in Instructional Development}

Instructional Systems are dynamic, interactive, interrelated components of learning resources (people, materials, content, devices, facilities, techniques to achieve pre-specified instructional objectives. Instructional Systems Development is the application of systems' development procedures (Analysis, Design, Develop/Produce, Evaluate, Utilize, Feedback, and Revise) of instructional systems. Basically, ISD models guide instructional developers in the instructional developmental process that vary in their purposes, amount of detail provided, degree of linearity in which they are applied, and their operational tools Gustafson \& Branch [3]. Such ISD models reflect the available technological learning resources, learning theories, learning tasks, and intended learning outcomes. Most of ISD models that came in the 70's, the 80's, and even in the 90's were developed to be suitable for early AV multimedia instructional systems of the 70 s, and computer based multimedia instructional systems. Practitioners and developers are facing difficulties in using such ISD models for developing eLearning virtual environments for education, training, and distance learning. So, developers of those ISD models should revise their ISD model to meet eLearning and distance learning innovations. In sum, ISD models are essential for instructional systems development to maintain quality and validity of those systems in practice and research. This research attempts to revise one of those ISD models to fit eLearning and distance learning environments' development.

\section{ISD Models in Developmental Research}

Developmental Research has been defined as "the systematic study of designing, developing, and evaluating instructional programs, processes and products that consistency and effectiveness" Seels \& Richey [4]. This means that the developmental research method depends on instructional development in order to answer research questions and to generate scientific knowledge. Developmental research has at least two types: Type I and Type II Richey [5]. Type I aims at developing instructional systems or instructional product and making context-specific conclusions (such as developing an eCourse), while Type II aims at conducting instructional development to answer research questions and generate new scientific knowledge about new evaluation processes, new instructional models, new design variables of instructional systems and learning environments, new learning and teaching models, and innovations to make generalized conclusions. Thus, developmental research methods always have two benefits: 1) Practical instructional technology solutions in complex contexts, and 2) Answering research questions, knowledge generations, and making generalized conclusions in our field. Reeves, Herrington, and Oliver [6] illustrated Van Den Akker [7] developmental research approach in four inter-related phases for researchers to do: 1) Analysis of practical problems, 2) Development of solutions with a theoretical framework, 3) Evaluation and testing of solutions in practice, and 4) Documentation and reflection to produce new design principles. Wang \& Hannafin [8] stated that design-based research encompass other research para- 
digms including developmental research and defined design-based research as systematic but flexible methodology aimed to improve educational practices through iterative analysis, design, development, and implementation that leads to contextually-sensitive design principles and theories. As a view, it is in the other way that developmental research methods encompass design-based researches and both of them are based on the instructional system development method. Development research method was described as a formal scientific research method in instructional technology by many instructional technology scholars such as $[9,10]$. The author of this article has concluded that developmental research method's steps are basically redefined to include three integrated research Methods: 1) Descriptive research methods for problem contextual analyses, content analysis 2) Systems development method/approach in terms of implementing instructional systems development models (ISD models), that includes formative evaluation methods and action research methods, and 3) Experimental research methods. So, the instructional systems development is the backbone of the developmental research method.

For both instructional systems development and developmental research method, the author has developed an ISD model for single lesson or unit [11] that has been used by several researcher for their researches on AV multimedia instructional systems (see Figure 1). This ISD model has been widely spread out among researchers in educational technology. It was based on: 1) Instructional Technology, in practice, is a dynamic process is based on the application of knowledge, use of human and non-human learning resources, active learner, and system's approach to achieve objectives and bring about effective learning, 2) Instructional Systems are dynamic, interactive, interrelated components of learning resources (people, materials, content, devices, facilities, techniques) to achieve pre-specified instructional objectives, 3) Instructional Systems Development are the application of systems' development procedures (Analysis, Design, Develop/Produce, Evaluate, Utilize, Feedback, and Revise) of instructional systems, and 4) Instructional Systems Design, if it isn't the Instructional Technology it is the core of it. Extensive use of this ISD model among our students at Ain Shams University in Cairo, has led Prof. Fateh-Elbab A. Sayed, who is considered the father of educational technology in Egypt and Arab world, to say in one of PhD final defense "now I can say that Ain Shams University is a scientific school of ISD research". Elgazzar (1995) ISD model was coupled with templates describing every single step in every developmental phase or one should say a practical guide.

Two main features led numerous researchers to select this ISD model, 1) its easiness because model had a practical guide and templates, and 2) researchers started to understand that a new direction in research methodology in their field which is developmental research has been growing since the 1994's Association of Educational Communications and Technology's definition of the field of Instructional Technology [4]. During the the period 1995-2002 many developments have taken place: 1) The growing of computer, based multimedia instructional systems in instructional technology research and development, 2) The stress on researches on design variables such as types of feedback, content organization and elaboration, learner control of learning, levels of interactivity, constructivism models, navigating types, computer based testing, user learner interface designs, eBooks, and so forth, 3) Affordability of digital learning resources, 4) Growing instructional software companies. In response to the above developments, the Author [12] made a second revision or version to Elgazzar (1995) ISD model in 2002. That second revision has resulted in Elgazzar (2002) ISD model (see Figure 2) of computer based multimedia instructional systems, that was very widely used by many researchers in Arab Countries. About five years later, this second revision of Elgazzar (2002) ISD model started to face problems in its implementations to meet new innovations of developing eLearning environments for both eLearning and distance learning. It is important here to define eLearning environments. An e-learning environment or virtual learning environment (VLE) is a co-operative/collaborative group or self interactive closed or open accessed learning system, web-based or hosted by a Learning Management System (LMS)/Learning Content Management System (LCMS) that provide learners' interaction with learning resources and activities, communication tools, evaluation and testing, learners' management and support, and it can take the of eCourse or eTraining program, or etc. to achieve objectives and intended learning outcomes. In fact, it is a learning system that operates in complex contexts.

Young researchers conducting developmental research on eLearning environments in Arab contexts began to suggest novice ISD models and immediately use them in their research without validation. Khamis [13] has warned all such researchers in their MA and $\mathrm{PhD}$ theses that it isn't acceptable for them to simply suggest and use their ISD model, but they should select the appropriate model based on careful analyses of available ones using a selection criterion. The core of this criterion is that the ISD model must be approved and its effectiveness has been validated - through field Instructional Development (ID) in several implementations in developmental researches. This situation encouraged the author to feel the problem of this research. 

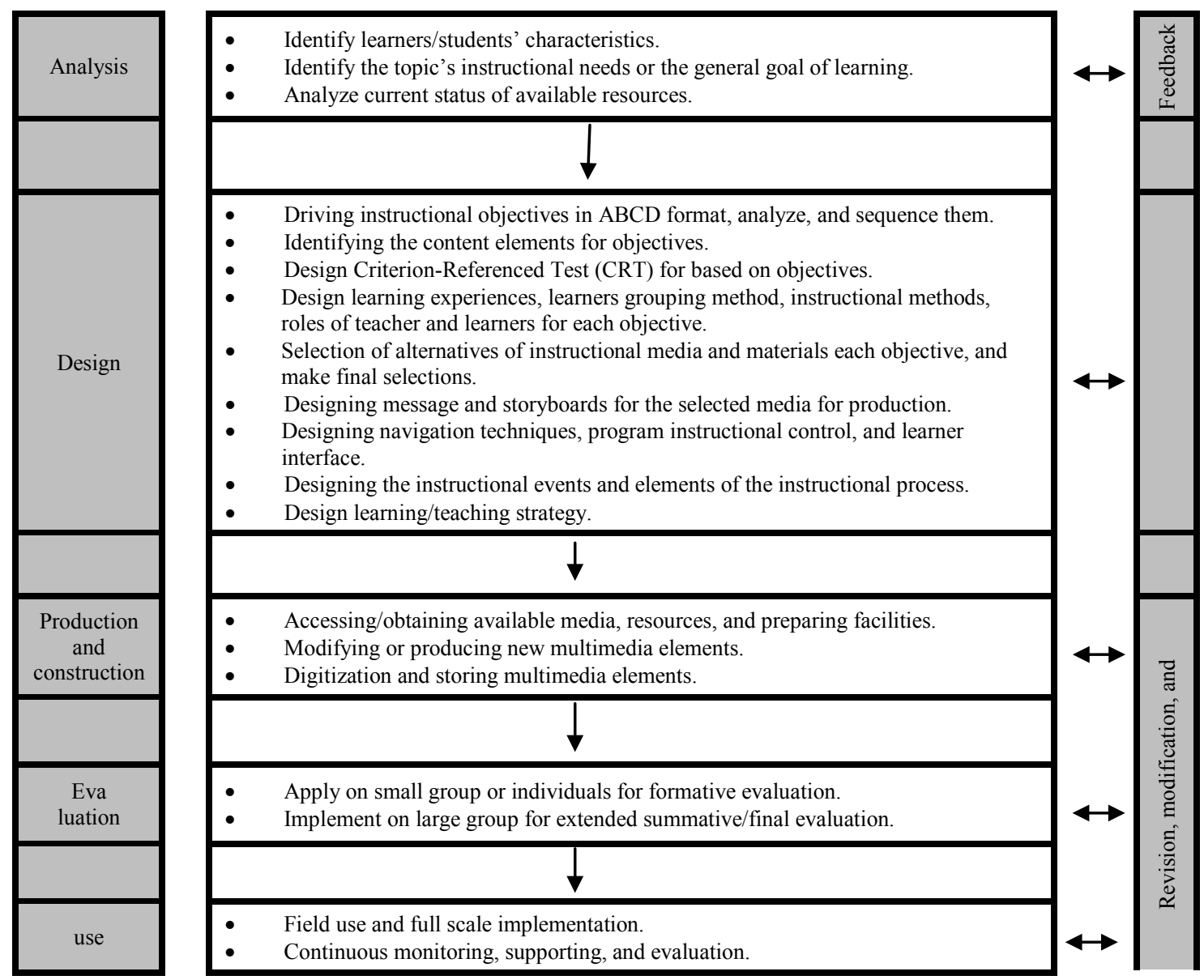

Figure 1. Elgazzar (1995) ISD Model for single lesson or Unit.

\section{The Research Problem}

Since these new eLearning environments are web-Based learning systems that basically have inter-related components that contain pre-defined objectives, eContent (learning resources, self or group activities) in lessons/ modules, Communication tools, evaluation and tests, and learners' management and support to achieve objectives. So, developing such eLearning environments needs appropriate ISD models. Researchers had to use Elgazzar (2002) since there was no ISD model directly addressed developing such environments. The author has clearly noticed while supervising PhD and MA theses in the past 10 years, some difficulties facing those researchers in applying that model in their developmental research on eLearning and distance learning environments. Then, the problem of this study was stated as that there was a need to revise Elgazzar (2002) ISD model to meet recent innovations in developing eLearning and distance learning environments.

\section{Research Procedures}

\subsection{Research Method}

Developmental research method was implemented that included, case studies, and descriptive research to report revisions of the Elgazzar (2002) ISD model to reach the new third revised Elgazzar (2013) ISD model through qualitative analyses.

\subsection{Research Tools}

An open answered Questionnaire that contained four questions about needed revisions of Elgazzar (2002) ISD 


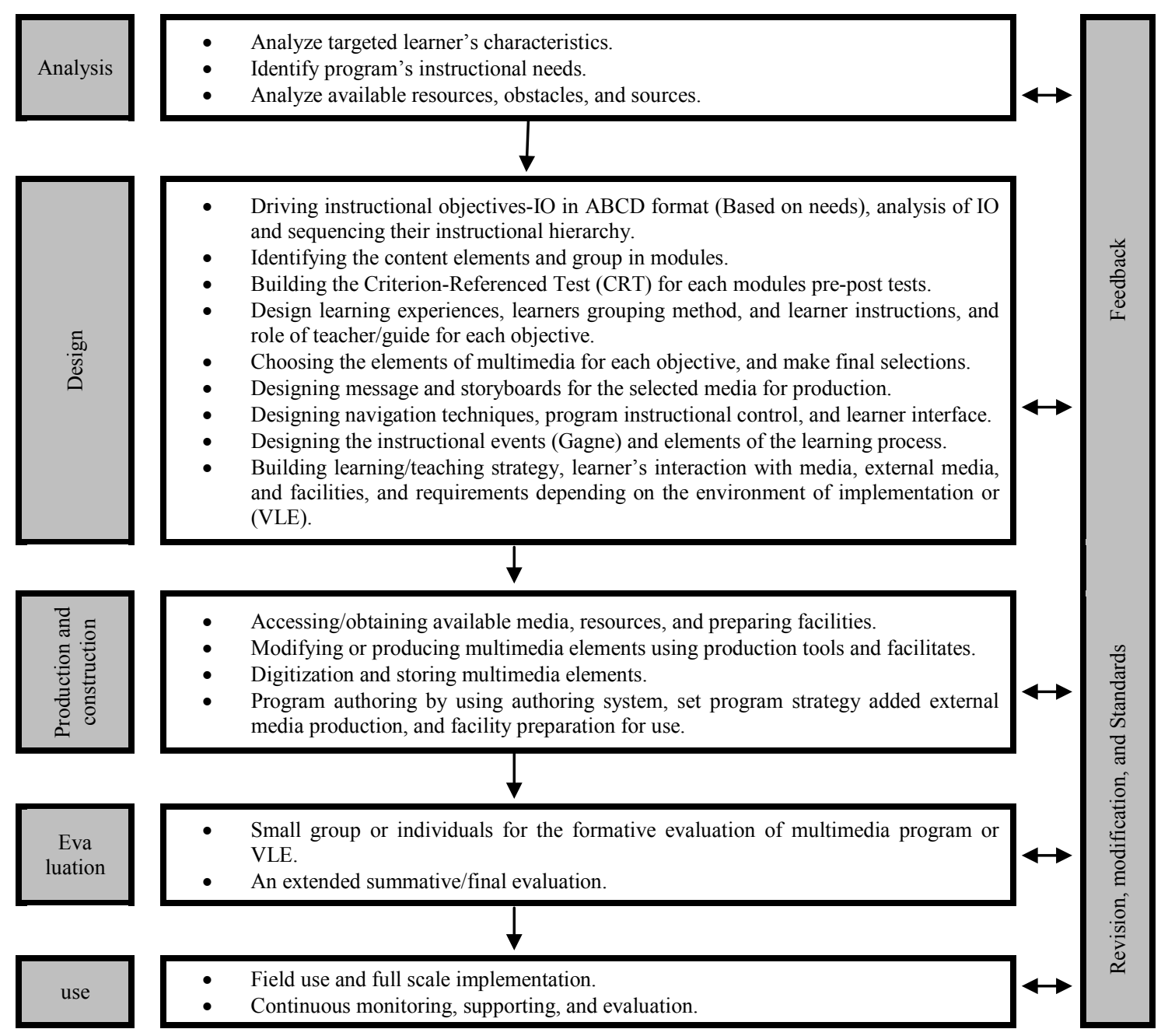

Figure 2. Elgazzar (2002) ISD model for computer-based multimedia programs.

model while its implementation in their Thesis: 1) What new steps did you add to the design phase? 2) What new steps did you add to the production phase? 3) What new actions did you add in the evaluation phase? 4) What new actions did you do in experimentations? Besides, the researcher used a Checklist to analyze the reported steps of the actual implementation of the ISD model's phases in their theses.

\subsection{Participants}

Participant cases were eight (8) PhD students who used Elgazzar (2002) ISD model under the author supervision (7 of them completed their theses) in their Theses. Five of them used MOODLE Learning Content Management System (LCMS) for their eLearning environment, while the other two developed their own eLearning environments as Websites. The eight cases as being my advisees, the implementation of the ISD model were done under my guidance step by step. Besides, two Associate Professors (Dr. A. M. Alagab and Dr. A. M. Nouby) of Instructional Technology and eLearning, Distance Teaching and Training Program, Arabian Gulf University participated as referees to approve the final third revised Elgazzar (2013) ISD model.

\subsection{Data Collection and Analyses}

The Questionnaire was e-mailed to all participant cases twice in October 2013, while the author started analyzing their theses reports on the implementations of the model in Chapter 4 using the Checklist on ISD model's phases. Names, Theses' titles, and universities of participant cases are: 
Altaban, M. A. (2012). The interaction between two digital storytelling designs via the web with the cognitive styles and its effects on acquiring knowledge and developing creative thinking among educational technology nstudents. Ph.D. Thesis, Cairo: Ain shams University (Arabic).

Eldigwy, K. (in progress). Effects of the interaction between two strategies of designing learner interface in web-based eLearning programs with learning styles on developing cognitive achievement, visual thinking, and reflections among preparatory stage pupils. Ph.D. Thesis, Cairo: Ain shams University (Arabic).

Hassouna, I. (2013). Effectiveness of (2 dimenthional/3 dimentional) learning objects' design in a webbased learning program for developing skills of using educational technology tools and visual thinking among Alaqsa university students. Ph.D. Thesis, Cairo: Ain shams University (Arabic).

Elhadedee, N. A. (2012). The Effect of Designing a web-based eLearning Program Utilizing Anchored Learning on developing Instructional Technology Graduate Students' competences of E-Course Administration in faculties of education. Ph.D. Thesis, Cairo: Ain-Shams University (Arabic).

Mansour, N. (2008). Developing distance learning eCourse via the internet and its effects on achievement among professional diploma in instructional technology. Ph.D. Thesis, Cairo: Ain shams University (Arabic).

Elghool, R. (2011). Effects of some strategies of working group in designing eTraining on developing skills of designing and applying web 2 services among faculty members. Ph.D. Thesis, Mansoura: Mansoura University (Arabic).

Rebhi, H. (2011). Effectiveness of web-base two collaborative learning strategies in developing knowledge generation and application skills among Alaqsa university students. Ph.D. Thesis, Cairo: Ain shams University (Arabic).

Mustafa, M. (2013). Interaction effects between some co-operative learning strategies and learning styles in a web-based program on developing problema solving skills in an AC technology course among technical secondary schools' students. Ph.D. Thesis, Cairo: Ain shams University (Arabic).

All participant cases answered the four questions and developed standards for their eLearning environments (see Table 1).

Analyses of Questionnaire answers and content analysis of reported implementations of ISD Checklists have resulted in agreed upon revisions in about (14) modifications in four phases of the model. In Analysis Phase, modifications: 1) Adopt or establish ISD's standards for eLearning Environment(EL) or VLE, 2) Analyze available digital resources, Learning Management System (LMS), Learning Content Management System (LCMS), and available Learning Objects (LO), obstacles, and Limitations. In Design Phase, modifications: 3) Design Evaluation and Tests: Criterion-Referenced Tests, and modules pre-post tests, 4) Designing for learning/ instructional models, design variables, learning theories, collaboration/cooperation, content structures, Gagne's events, or any design innovations, 5) Select and design synchronus/asynchronous communication tools, 6) Design learners' registration and management, grouping, and learners' support systems, 7) Design layout of components, navigation, guides and help, glossaries, and eLearning environment open/closed access, 8) Design basic

Table 1. Participants, LCMS, answered questions, and standards.

\begin{tabular}{cccccccc}
\hline \multirow{2}{*}{ No. } & \multirow{2}{*}{ Name, Year } & \multirow{2}{*}{ LCMS } & \multicolumn{5}{c}{ Answered Questions } \\
\cline { 5 - 8 } & & & $1^{\text {st }}$ & $2^{\text {nd }}$ & $3^{\text {rd }}$ & $4^{\text {th }}$ & Standards \\
\hline 1 & M. Altaban, 2012 & Yes & Yes & Yes & Yes & Yes & Yes \\
2 & I. Hassouna, 2013 & Web & Yes & Yes & Yes & Yes & Yes \\
3 & K. Eldigwy, Prog. & Web & Yes & Yes & Yes & Yes & Yes \\
4 & N.Elhadedee, 2007 & Yes & Yes & Yes & Yes & Yes & Yes \\
5 & N. Mansour, 2008 & Yes & Yes & Yes & Yes & Yes & Yes \\
6 & R. Elghoole, 2011 & Yes & Yes & Yes & Yes & Yes & Yes \\
7 & H. Mahdi, 2010 & Yes & Yes & Yes & Yes & Yes & Yes \\
8 & M. Mustafa, 2013 & Yes & Yes & Yes & Yes & Yes & Yes \\
\hline
\end{tabular}




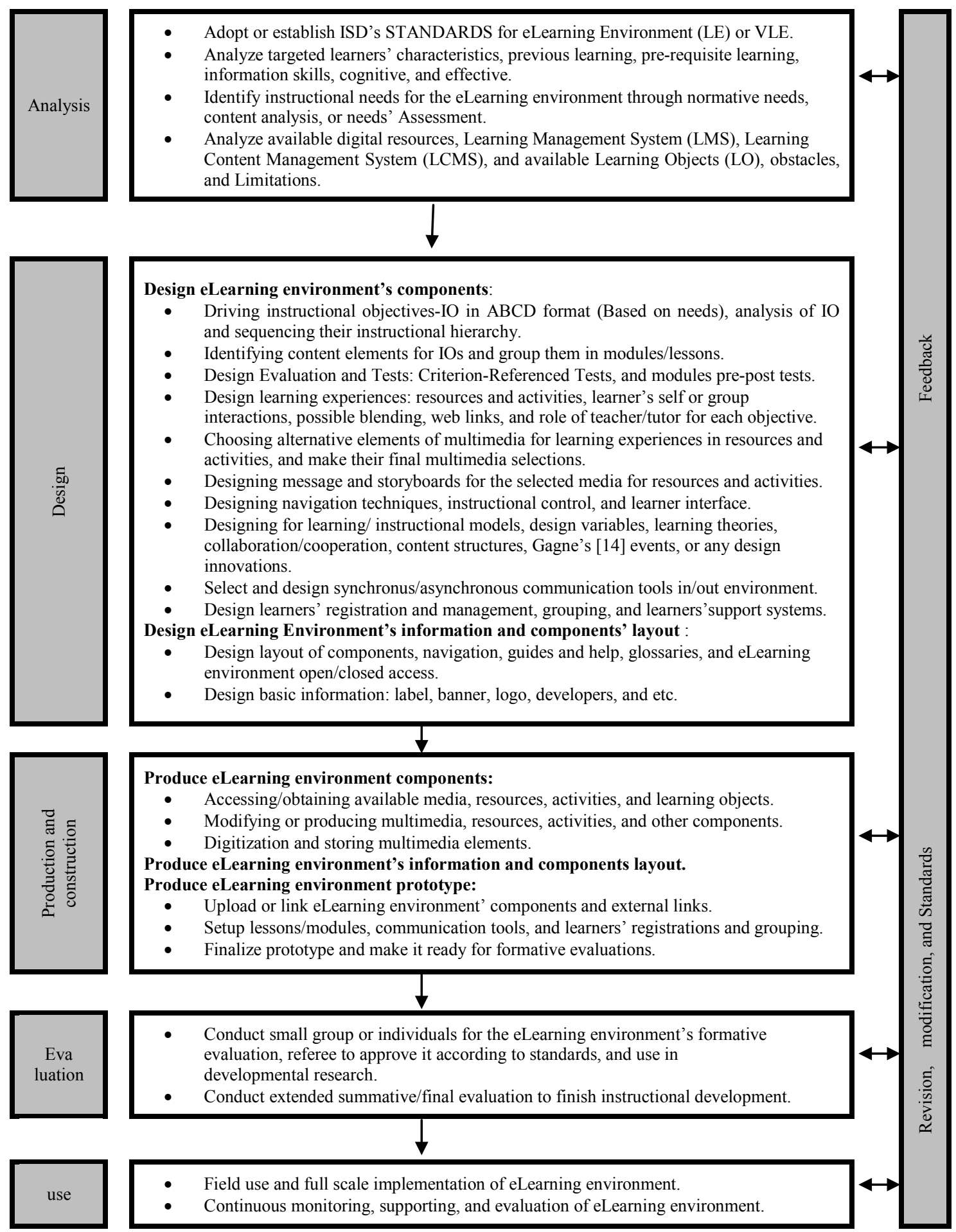

Figure 3. Elgazzar (2013) ISD model for developing eLearning environments (Third Revision).

information: label, banner, logo, developers, and etc. In Production and Construction Phase, modifications: 9) Produce eLearning environment's information and components layout, 10) Upload or link eLearning environment' components and external links, 11) Setup lessons/modules, communication tools, and learners' registrations and grouping, 12) Finalize prototype and make it ready for formative evaluations. in Evaluation Phase, modifications: 13) Conduct small group or individuals for the eLearning environment's formative evaluation, 
referee to approve it according to standards, and use in developmental research, 14) Conduct extended summative/final evaluation to finish instructional development.

\subsection{Prototype of the Revised Elgazzar (2013) ISD Model}

The author put all the above agreed upon (14) revisions and the eLearning environment's components, as well as involved steps on the Elgazzar (2002) ISD model, and established a prototype of the third revised Elgazzar (2013) ISD model. This prototype ISD model was formatively reviewed with some key participant cases and changes have been done to the prototype. Then, the prototype of Elgazzar (2013) ISD model was ready for refereeing.

\subsection{Final Revision and Approval of Elgazzar (2013) ISD Model}

The prototype of Elgazzar (2013) ISD model was refereed by the two participant colleagues in face to face meetings. They gave valuable suggestions and modifications to the prototype. All of these modifications were done to the ISD model. Finally, the Elgazzar (2013) ISD model, third revision, was approved by them (see Figure 3). The third case (K. Eldigwy) has started in applying it in his Ph.D. (In progress). Further guides and templates for its implementation were being done to help practitioners and developmental researcher that were difficult to include in this paper.

\subsection{Recommendations and Further Researches}

Some recommendations can be driven out of this research about the third revision Elgazzar (2013) ISD model:

1) Practitioners and Developers of eLearning environments should use this model individually or in teams in developing eLearning environments for eCourses and eTraining in schools and Higher Education Institutes.

2) Researchers should use this model in their Developmental Research Methods in developing eLearning environments for eCourses and eTraining researches in schools, Higher Education Institutes, distance learning.

3) Future researches should be done to make revisions of this model for use in Mobile Learning, Intelligent (Smart), and Clouding eLearning environments.

\section{Acknowledgements}

This research has been done as a part of King Hamad Academic Chair of eLearning activities, Arabian Gulf University. The author is deeply giving special thanks to Arabian Gulf University for supporting him to attend the CITE 2014.

\section{References}

[1] Galbraith, J.K. (1967) The new industrial state. Houghton-Mifflin, Co., Boston, Mass.

[2] El-Gazzar and Abdel-Latif, E. (2010) Research Directions in Standards of Designing Environment for Applying Information Communications and Technology (ICT) in Instruction and Training. The First International Symposium: ICT Applications in Instruction and Training, Faculty of Education, King Saud University, Riyadh, KSA.

[3] Gustafson, K.L. and Branch, R.M. (1997) Survey of instructional development models. 3rd Edition, ERIC Clearinghouse on Information and Technology, Syracuse, New York.

[4] Seels, B.B. and Richey, R.C. (1994) Instructional technology: The definition and domains of the field. AECT, Washington DC.

[5] Richey, R.C. (1994) The developmental research: The definition and scope. ERIC Clearinghouse on Information and Technology, Syracuse, New York.

[6] Reeves, T.C., Herrington, J. and Oliver, R. (2004) A developmental research agenda for online collaborative learning. Educational Technology Research and Development, 52, 53-65. http://researchrepository.murdoch.edu.au./5412/ http://dx.doi.org/10.1007/BF02504718

[7] Van Den Akker, J. (1999) Principles and methods of development research. In: Van Den Akker, J., Nieveen, N., Branch, R.M., Gustafson, K.L. and Plomp, T., Eds., Design Methodology and Developmental Research in Education and Training, Kluwer Academic Publishers, The Netherlands, 1-14. 
[8] Wang, F. and Hannafin, M.J. (2005) Design-based research and technology-enhanced learning environments. Educational Technology Research \& Development, 53, 5-23. http://dx.doi.org/10.1007/BF02504682

[9] Richey, R.C. and Klein, J.D. (2005) Developmental research methods: Creating knowledge from instructional design and development practice. Journal of Computing in higher Education, 16, 23-38. http://dx.doi.org/10.1007/BF02961473

[10] Richey, R.C., Klein, J. and Nelson, W. (2004) Developmental research: Studies of instructional design and development. In: Jonassen, D., Ed., Handbook of Research for Educational Communications and Technology, 2nd Edition, Chapter (41), Lawrence Erlbaum Associates, Inc., Mahwah, 1099-1130.

[11] El-Gazzar and Abdel-Latif, E. (1995) An exploratory study of using an ISD model in instructional technology among female student teachers, Faculty of Education, United Arab Emirates University. Journal of Instructional Technology, Egyptian Association of Educational Technology, 5, 1-2.

[12] El-Gazzar and Abdel-Latif, E. (2002) Effectiveness of using multimedia computer assisted instruction on acquision of some levels of learning of scientific concepts according to Frayer's Model of Concepts' Evaluation. Journal of Education, Scientific Refereed Journal, Faculty of Education, Al-Azhar University, Cairo, 155, 37-83.

[13] Khamis, M.A. (2010) An important warning to all researchers in instructional technology field "Don't Use This Model”. Journal of Instructional Technology, Egyptian Association of Educational Technology, 20, 291-302.

[14] Gagne, R.M. (1977) The conditions of learning. 3rd Edition, Holt, Rinehart, and Winston, New York. 